\title{
Pengujian Association Clasification Dalam Meningkatkan Kualitas Minyak Sawit Sebagai Bahan Dasar Biodisel
}

\author{
Adi Fitra Andikos ${ }^{1}$, Helly Andri ${ }^{*}$ \\ ${ }^{1}$ Prodi Manajemen Pendidikan Islam, STITNU Sakinah Dharmasraya, Sumatera Barat, Indonesia \\ ${ }^{2}$ Fakultas Ilmu Komputer, Universitas Dharmas Indonesia, Sumatera Barat, Indonesia \\ E-mail: ${ }^{1}$ andikos@stitnu-sadhar.ac.id, ${ }^{2}$ Ad_sitra@yahoo.com*
}

\begin{abstract}
Abstrak
Peran kegiatan usaha minyak dan gas bumi (migas) di Indonesia selalu memberi pengaruh terhadap Income negara dan sangat berpengaruh terhadap perekonomian nusantara.Pada saat ini, Indonesia adalah produsen dan eksportir minyak sawit yang terbesar di seluruh dunia. Minyak sawit adalah salah satu jalan untuk mengatasi masalah perminyakan di indonesia. Untuk mengkomersilkan biodisel masih terkendala karena ketersediaan bahan baku yang rendah biaya sangat susah didapatkan. Penggabungan Asam minyak sawit mentah dan Lumpur sawit mentah adalah salah satu menagatasi masalah bahan baku untuk produksi energi terbarukan. Untuk mendapatkan pencampuran kualitas yang maksimal dibutuhkan sebuah metode komputer. Dalam penelitian ini penulismenggunakan metode studi analisa dengan pendekatan Association Classifikasi dengan pengujian Improved algoritma Apriori dalam menambang dataset minyak sawit. Aplikasi Data Mining dapat digunakan untuk menampilkan informasi peningkatan kualitas asam minyak sawit dengan kualitas tinggi sebagai bahan dasar biodiesel di mana informasi tersebut dilihat dari nilai support dan confidence antar item. Algoritma M-Apriori tidak dapat membaca data yang bersifat continous. Asam minyak sawit mentah jenis Esteridikasi yang Kadar asam lemaknya >60 dan Abu tandan 51-100 g/mol maka Kualitas biodiesel dengan ket Hasil naik metil Ester meningkat sebanyak 100\% (confidence: 1). Dari data yang dihitung secara manual, tidak ditemukan hubungan asosiasi.
\end{abstract}

Kata Kunci: Data Mining, Asociation Classification, Improv Apriori, Asam Minyak mentah, Abu tandan sawit.

\section{Abstract}

The role of oil and gas business in Indonesia has always influenced the source of revenue from the country and energy sources for the national economy. In the 1970 's to the 1990 's and mid-1990 's, it was characterized by the high dependence of the national economy on oil and gas revenues, triggering massive oil and gas-producing. Currently, Indonesia is the largest palm oil producer and exporter in the world. Palm oil is one of the roads to overcome the problem of petroleum in Indonesia. To commercialize plants is still constrained because the availability of low raw material costs very hard to get. The amalgamation of crude palm oil and crude palm sludge is one of the problems of raw materials for renewable energy production. This lowlevel oil has great potential as a raw material for biodiesel production. To get the maximum quality mixing required a computer method. The method used in this study is analysis study with the Association classification approach by testing Improved Apriori algorithm in mining palm oil dataset. In this research using Data Mining application so that can be used to display the information of quality improvement of palm oil acid with high quality as a biodiesel base where the information is seen from the value of support and Confidence between items. M-Apriori algorithm can not read the continous data, so it must be done transformation first, one of them using the help of discreetization technique. Crude palm oil acid type esteridication which is fatty acid levels $>60$ and Abu bunches 51-100 g/mol then the quality of biodiesel with the result of rising methyl Ester increases by as much as $100 \%$ (confidence: 1 ). From data that is calculated manually, no relationship is found Association.

Keywords: Data Mining, Classification asociation, priori Improv, crude oil acid, ash bunches palm.

\section{PENDAHULUAN}

Peran kegiatan usaha minyak dan gas bumi (migas) di Indonesia selalu memberi pengaruh terhadap Income negara dan terhadap perekonomian nusantara maupun sumber energi bagi perekonomian nasional. Sesuai perannya, periode 1970-an hingga 1990-an terjadi ketergantungan perekonomian nusantara terhadap migas sehingga memicu pemroduksian migas besar-besaran pada tingkat kapasitas maksimal [1]. Seirama dengan kondisi tersebut, industri migas yang dimainkan pelaku bisnis tumbuh dan berkembang pesat mengejar peluang yang sangat menjanjikan. Pesatnya industri migas juga mengakibatkan pengurasan migas sering kali jauh di atas tingkat produksi optimum dan pada akhirnya banyak kalangan mulai menyadari bahwa cadangan migas telah menurun secara drastis.

Minyak nabati merupakan salah minyak yang paling banyak gunakan dan konsumsi di dunia terutama Negara indonesia. Produksi minyak nabati dunia didominasi oleh Negara Indonesia dan Malaysia dan pada saat ini, Negara Indonesia adalah salah satu penghasil dan eksportir minyak sawit terbesar di dunia. Minyak nabati merupakan salah satu jenis minyak mengandung asam lemak, sehingga mempunyai ruang yang besar untuk dikembangkan sebagai bahan baku bahan bakar minyak atau biodiesel dari minyak nabati. Minyak nabati diketahui memiliki kelebihan ramah terhadap lingkungan, sehingga tidak mencemari udara, ekologi, sehingga Biodiesel dari minyak nabati sangat efektis untuk minyak masa depan karena dapat diperbaharui.

Untuk membuat biodiesel membutuhkan bahan baku yang konsisten. Penggabungan asam minyak sawit mentah dan lumpur sawit mentah adalah salah satu menagatasi masalah bahan baku untuk produksi energi terbarukan. Minyak tingkat rendah ini memiliki potensi besar sebagai bahan baku untuk produksi biodiesel.

Saat ini penggabungan asam minyak sawit mentah dan lumpur sawit mentah telah terjadi penumpukan data sehingga menjadi gudang data di perusahaan - perusahaan besar di indonesia. Data Mining merupakan teknologi baru yang sangat berguna untuk menambang data dan dapat memberikan pengetahuan berharga atau penting dalam 
tumpukan data. Menurut andika, Data Mining adalah sutu proses mengeksplorasi basis data untuk menemukan pola-pola yang tersembunyi, mencari informasi memprediksi yang meungkin saja terlupakan [2].

Untuk menerapkan konsep data mining banyak cara yang dapat digunakan diantaranya adalah menggunakan konsep beberapa algoritma yang ada pada data mining. Suatu kriteria yang diberikan dalam pengambilan keputusan adakalanya melibatkan penggunaan variabel tujuan yakni digunakan untuk meningkatkan persisters dan non - persisters, meskipun model terbaik atau aturan khas untuk persisters dan non - persisters sangat berguna dalam memahami tetapi mereka tidak membantu dalam memahami apa yang ada dalam. Abdel, et al menyebutkan bahwa Associative classification (AC) adalah cabang dalam data mining yang memanfaatkan metode association rule discovery dalam masalah klasifikasi [3].

Beberapa studi memberikan bukti bahwa teknik AC dapat memberikan model klasifikasi yang lebih akurat dibandingkan dengan teknik-teknik klasifikasi tradisional seperti decision tree, rule induction, dan pendekatan probalistik. Membangkitkan frequent itemset merupakan satu bagian dari fase pertama dalam metode AC, yang disebut fase rule generation. Fase rule generation meliputi metode untuk menemukan frequent itemset dan metode untuk mengekstrak rule dengan tujuan membangkitkan himpuan class association rule (CAR) [4].

Dengan menggunakan AC maka akan dilakukan pengambilan informasi yang hasil penelitiannya dapat dijadikan contoh dalam masalah pengelompokan yang melibatkan data-data yang pasti.

Ada banyak metode Associative classification mining seperti CBA, CMAR, MCAR, L3, dan sebagainya. Metode-metode tersebut secara umum menggunakan beberapa pendekatan berbeda dalam pembangkitan rule (CAR). Dalam penelitian ini penulis melakukan pendekatan Associative classification dengan mengimprov Apriori (M-Apriori) untuk meningkatkan kualitas asam minyak nabati sebagai bahan dasar biodiesel.

\section{METODE PENELITIAN}

Menurut Liu et al metode AC pertama yang ada pada algoritma Apriori adalah metode CBA. Prinsip Apriori menyatakan bahwa jika sebuah itemset adalah frequent, maka semua subsetnya juga frequent [3]. Algoritma $C A R$ generation dari metode CBA pada Gambar 1.

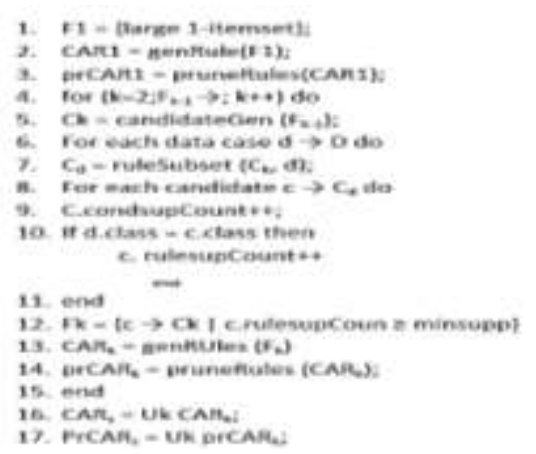

Gambar 1. Algoritma Rule Generation CBA

Gambar di atas adalah Algoritma lain dari Apriori atau M-Apriori (improved Apriori) [7]. Selama ini algoritma Apriori mudah untuk mengekstrak dan sangat sederhana dalam menambang rule frequen itenset di database namun mengabiskan waktu yang cukup lama. Metode ini membuktikan dapat mengurangi pemakain waktu dan membuat algoritma apriori lebih efisien. Sistem dalam penerapan algoritma M-Apriori (improved Apriori) pada penelitian ini di jelaskan pada gambar 2.

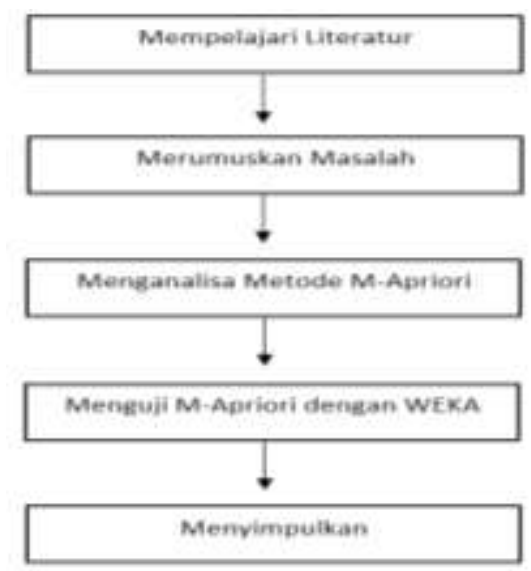

Gambar 2. Kerangka kerja 
Pada gambar di atas merupakan langah-langkah dalam melakukan penelitian ini yang mulai dari mempelajari literatur referensi, merumuskan masalah, merumuskan masalah, menganalisa sejauh mana manfaat metode M-apriori dalam pengambilan keputusan sampel, menguji algoritma M-Apriori, dan terakhir mengambil kesimpulan. Penerapan model M-Apriori pada penelitian ini dapat di ilustrasikan seperti pada tabel 1.

Tabel 1. Proses M-Apriori

\begin{tabular}{ccc}
\hline Item & Apriori & M-Apriori \\
\hline 1-itemset & 45 & 45 \\
2-itemset & 54 & 25 \\
3-itemset & 36 & 14 \\
Sum & 135 & 84 \\
\hline
\end{tabular}

Pada tabel $1 \mathrm{di}$ atas adalah sebagai ilustrasi dari algoritma M-Apriori, perhatikan contoh dataset training pada Tabel 1. Misalkan diberikan nilai minsupp threshold $3 \%$ dan mempunyai 9 transaksi. Pertamatama dataset discan untuk memperoleh himpunan frequent 1 -itemset $(F 1)$. Setelah itu nilai confidence dari $F 1$ dihitung. $F 1$ yang mempunyai nilai confidence lebih besar atau sama dengan nilai minconf threshold dibangkitkan sebagai $C A R$ 1itemset. Item yang dibangkitkan sebagai F1 adalah sebanyak 3 tabel. Pada tabel.1 di atas dari M-Apriori contoh dataset training. Misalkan dari transaksi tersebut maka mendapatkan 3-itemset (1, 2, 3) yang Akan diujikan kedalam algoritma M-Apriori.

\section{ANALISA DAN PEMBAHASAN}

\subsection{Associative Classification}

Associative classification adalah kasus khusus dari association rule mining dimana hanya atribut kelas yang digunakan sebagai sisi kanan rule, sebagai contoh, $X \Rightarrow Y, Y$ harus merupakan atribut kelas [5]. Misalkan dataset training $D$ mempunyai $m$ atribut/item berbeda, $I=\left\{i_{1}, i_{2} \ldots \ldots, i_{m}\right\}$ dan $C$ adalah daftar dari label kelas. Banyaknya baris dalam $D$ dinotasikan sebagai $|D|$. Atribut dapat bertipe kategorik atau kontinu. Pada kasus atribut bertipe kategorik, semua kemungkinan nilai dipetakan ke himpunan bilangan integer positif. Untuk atribut yang kontinu, atribut ini harus dideskritisasi untuk diubah ke bentuk kategorik.

Dalam masalah associative classification, setiap transaksi mengandung subset dari itemitem yang dipilih dari $I\left(d_{i}\right)$ dan label kelas $c$. Kumpulan dari nol atau lebih item disebut itemset. Itemset disebut frequent itemset jika nilai support dari itemset tersebut melampaui nilai minimum support (minsupp) threshold. Rule $r$ disebut frequent rule jika nilai rule support dari $r$ melewati nilai minsupp threshold. Sebuah rule diekstrak sebagai Class Association Rules (CAR) jika nilai support dan confidence dari $r$ melewati nilai minsupp and minimum confidence (minconf) threshold.

\subsection{Asam Minyak Nabati Mentah}

Minyak nabati dapat merupakan salah satu hasil tanaman yang potensial sebagai sumber hidrokaarbon yang potensial sebagai sumber hidrokarbon atau sumber energi di Indonesia. Bahan dasar biodiesel yang tersedia saat ini dan sangat efektif dikembangkan adalah Elais gueneensis Jacq atau kata lain kelapa sawit. Tetapi penggunaan yang kompetitif terhadap minyak sawit untuk sektor pangan menjadikan minyak sawit sulit untuk dikembangkan sebagai bahan bakar minyak. Dengan demikian perlu dicari alternatif lain dari minyak sawit. Sludge oil kelapa sawit sangat berpotensi untuk ditingkatkan nilai gunanya berupa lumpur padat dari limbah akhir pengolahan kelapa sawit menjadi minyak sawit mentah [1], namun memproduksi biodiesel, dan memiliki beberapa cara [6]:

1. Proses transesterifikasi adalah menggunakan teknologi pilihan dan proses yang paling ekonomis karena tingkat konversi hingga 98\%. Hal ini membutuhkan suhu rendah dan tekanan, yang mengarah pada penggunaan peralatan biasa .

2. Proses katalis asam dapat menghasilkan biodiesel melalui baik esterifikasi dan transesterifikasi, tetapi sangat lambat membutuhkan terlalu banyak waktu hingga satu hari untuk Penyelesaian. Hal ini juga lebih sulit daripada basis-katalis transesterifikasi, membutuhkan peralatan dengan biaya tinggi.

3. Transesterifikasi enzimatik telah mendapatkan pengetahuan baru-baru ini, terutama karena menghasilkan lebih sedikit limbah, mengkonsumsi lebih sedikit energi, dan telah mendapat efisiensi waktu dan selektivitas tinggi.

4. Produksi biodiesel menggunakan katalis juga menarik karena kegunaan mengembalikan katalis, dan fakta bahwa menghasilkan biodiesel dan gliserol menggunakan katalis lebih murni dan memiliki kualitas yang sangat tinggi.

5. Metode supercritical metanol adalah teknik lain dari membuat biodiesel tapi kali ini tanpa menggunakan katalis apapun. metode ini menawarkan efisiensi tinggi hingga 100\% dan ramah lingkungan. langkah ini menghilangkan netralisasi, pencucian dan Pengeringan. Bahan baku air dan tidak berpengaruh pada reaksi dan trigliserida secara bersamaan ke biodiesel. Namun tangki reaksi harus berukuran besar karena tingginya 
kuantitas alkohol yang digunakan sehubungan dengan minyak (hingga 42:1), tekanan tinggi lebih dari 80 atmosfer, dan suhu tinggi hingga 350-400oC. Metode ini membutuhkan pengoperasian dan biaya tinggi.

\section{IMPLEMENTASI}

Adapun data yang digunakan dalam penelitian ini merupakan data asam minyak sawit mentah dan lumpur sawit mentah pada PT. Dharmasraya Lestarindo 1 dan 2 yang diambil dengan Cara wawancara dan data yang ada pada pada PT. Dharmasraya Lestarindo 1 dan 2. Proses penambangan data asam minyak sawit mentah dan lumpur sawit mentah pada PT. Dharmasraya Lestarindo sebelumnya tidak pernah dilakukan namun data asam minyak sawit mentah dan lumpur sawit mengalami penumpukan data pada PT. Dharmasraya Lestarindo.

Proses pengelompokan dalam penambangan data asam minyak sawit mentah dan lumpur sawit dikelompokkan menjadi beberapa kriteria:

1. Asam minyak sawit mentah

2. Kadar asam lemak bebas

3. lumpur sawit $=$ Abu tandan $\mathrm{g} / \mathrm{mol}$

4. Kualitas Biodiesel

Dari kriteria di atas dapat dirumuskan sebanyak 12 kelompok dengan seperti pada tabel 2 berikut.

Tabel 2. Pra proses Data Bahan dasar biodiesel

\begin{tabular}{clccl}
\hline \multirow{2}{*}{ Kelompok } & Asam minyak sawit mentah & Kadar asam lemak & Abu tandan g/mol & \multicolumn{1}{c}{ Kualitas Biodiesel } \\
\hline 1 & Esteridikasi & $>60$ & $>50$ & Hasil Bagus metil Ester Meningkat \\
2 & Esteridikasi & $>60$ & $<50$ & Hasil Sedang metil Ester tetap \\
3 & transesterifikasi & $>60$ & $<50$ & Hasil Menurun metil Ester Menurun \\
4 & Esteridikasi & $>60$ & $<50$ & Hasil Sedang metil Ester tetap \\
5 & Esteridikasi & $40-59$ & $>50$ & Hasil Bagus metil Ester Meningkat \\
6 & Esteridikasi & $40-59$ & $>50$ & Hasil Bagus metil Ester Meningkat \\
7 & Esteridikasi & $40-59$ & $<50$ & Hasil Bagus metil Ester Meningkat \\
8 & transesterifikasi & $<40$ & $<50$ & Hasil Menurun metil Ester Menurun \\
9 & transesterifikasi & $<40$ & $<50$ & Hasil Menurun metil Ester Menurun \\
10 & transesterifikasi & $<40$ & $<50$ & Hasil Menurun metil Ester Menurun \\
11 & transesterifikasi & $<40$ & $>50$ & Hasil Bagus metil Ester Meningkat Menurun \\
12 & Esteridikasi & &
\end{tabular}

Berdasarkan kriteria PT. Dharmasraya Lestarindo, bahan dasar biodiesel dapat dilihat dari Asam minyak sawit mentah, Kadar asam lemak, Abu tandan g/mol dan Kualitas Biodiesel. Dari tabel 2 data bahan dasar biodiesel di atas, maka data digunakan untuk penambangan terlihat pada tabel 3.

Tabel 3. Data yang digunakan

\begin{tabular}{cl}
\hline Atribut & \multicolumn{1}{c}{ Keterangan } \\
\hline Asam minyak sawit mentah & Esteridikasi dan transesterifikasi merupakan salah satu cara yang ditempuh untuk membuat Ester \\
& metil pada minyak sawit \\
Kadar asam lemak & Persentasi dari Esteridikasi dan transesterifikasi \\
Abu tandan g/mol & Merupakan penunjukan komponen utama metil ester yang dihasilkan adalah metil kaprilat, metil \\
& kaprat, metil laurat, metil miristat, metil palmitat, metil oleat dan metil stearat \\
Kualitas Biodiesel & Merupakan hasil dari pengkategorian tingkat Ester metil \\
\hline
\end{tabular}

Algoritma m-apriori tidak mengenal data-data literatur, dengan demikian data hasil wawancara yang telah dikumpulkan terlebih dahulu dikelompokkan berdasarkan kelompok nilai pada tabel 4 untuk mempermudah penghitungan dan pengelompokan data.

Tabel 4. Kategori penambangan

\begin{tabular}{|c|c|c|c|c|}
\hline Range & Asam minyak sawit mentah & Kadar asam lemak & Abu tandan $\mathrm{g} / \mathrm{mol}$ & Kualitas Biodiesel \\
\hline $\mathrm{X}$ & Asam minyak sawit mentah jenis Esteridikasi & $>60$ & $51-100$ & $\begin{array}{l}\text { Hasil Bagus metil Ester } \\
\text { Meningkat }\end{array}$ \\
\hline $\mathrm{Y}$ & Asam minyak sawit mentah jenis transesterifikasi & $40-50$ & $41-50$ & $\begin{array}{l}\text { Hasil sedang metil Ester } \\
\text { tetap }\end{array}$ \\
\hline $\mathrm{Z}$ & $\begin{array}{c}\text { Asam minyak sawit mentah jenis Esteridikasi dan } \\
\text { transesterifikasi }\end{array}$ & $<40$ & $0-40$ & $\begin{array}{l}\text { Hasil Menurun metil Ester } \\
\text { Menurun }\end{array}$ \\
\hline
\end{tabular}

Kemudian dengan menggunakan Microsoft Excel dilakukan transformasi data tabel 4 dengan menggunakan ukuran nilai tabel 3, yang hasilnya ditampilkan pada table 5. tujuannya adalah untuk mempermudah penggalian Knowledge. 1-itemset ditetapkan minimum support $=0,2(20 \%)$ sehingga itemset yang tersisa dengan metode Apriori 18 dan metode M-Apriori juga 18 sebanyak 18 , selanjutnya dicari frequent 2-itemset (F2), antara lain ditetapkan minimum support $=0,2(20 \%)$ sehingga itemset yang tersisa dengan metode Apriori 28 dan metode M- 
Apriori sebanyak 12 Selanjutnya dicari frequent 3-itemset (F3) dengan melakukan pemangkasan item yang mempunyai nilai support lebih kecil dari nilai minimum support akan dihapus ditetapkan minimum support $=0,2$ (20\%) sehingga itemset yang tersisa dengan metode Apriori 48 dan metode M-Apriori sebanyak 9 dan yang terakhir frequent 4-itemset (F4) ditetapkan minimum support= 0,2 (20\%) sehingga itemset yang tersisa dengan metode Apriori 54 dan metode M-Apriori sebanyak 6. Perbandingan apriori dan $\mathrm{m}$-apriori dalam menscan data pada PT. Dharmasraya Lestarindo 1 dan 2 dilihat pada tabel 5.

Tabel 5. Nomor transaksi pada percobaan scen data

\begin{tabular}{lcc}
\hline & Ariori & M-Apriori \\
\hline 1 Itemset & 18 & 18 \\
2 Itemset & 28 & 12 \\
3 Itemset & 48 & 9 \\
4 Itemset & 54 & 6 \\
\hline
\end{tabular}

Pada penelitian ini kami mencoba menerapkan Apriori asli dan kami bandingkan dengan M-apriori, dan hasilnya kami mendapatkan 4 transaksi:

T1: 380 transaksi.

T2: 578 transaksi.

T3: 976 transaksi.

T4: 1229 transaksi

Dari ke empat transaksi tersebut yang memenuhi confidence paling rendah (0.7) 70\% hanya 48 Item

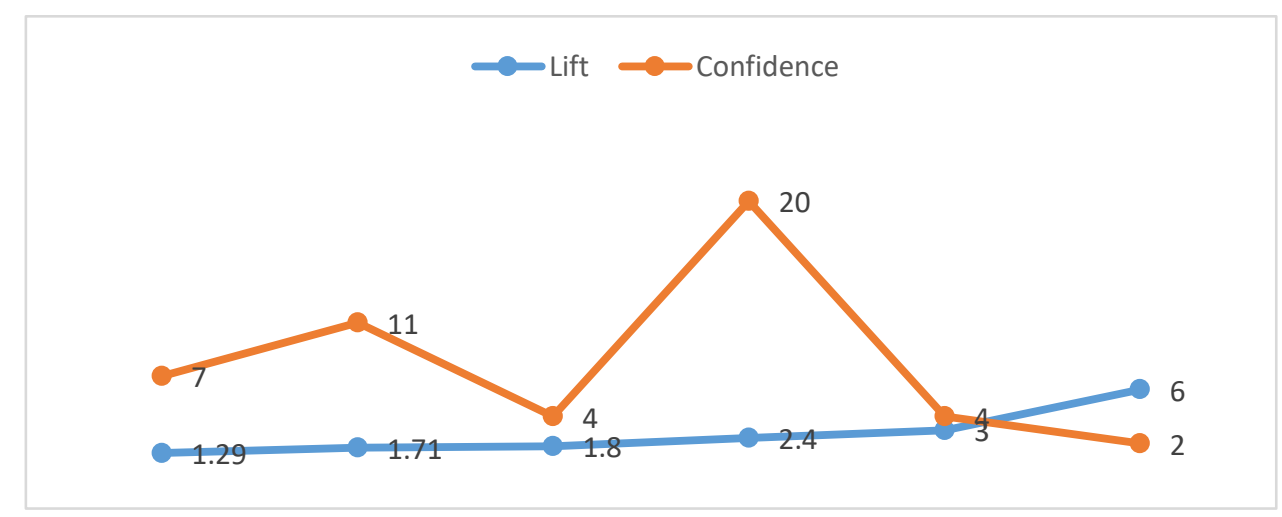

Gambar 3. Trasaksi yang memenuhi standar confidence

Hasil Perhitungan Asosiasi Classification yang di gambarkan diatas, bisa dilihat menghasilkan rule sebanyak 48 buah, yang mana confidence diatas $70 \%$ lah yang akan diambil karena pengaturan confidennya $(0,7)$ $70 \%$ dan dapat di simpulkan bahwa metode Associative classification dalam menambang asam minyak kelapa sawit dengan algoritma M-Apriori sangat efektif sehingga lebih efisien untuk mengambil keputusan.

\section{KESIMPULAN}

Penelitian ini didadani oleh kemenristekdikti dan Diktis pada tahun anggaran 2017. Penambang minyak berkualitas rendah dengan pendekatan Associative classification menggunakan metode M-Apriori sangat efektif dari segi waktu di bandingkan dengan metode Apriori, penelitian ini bermaksud untuk mampu meningkatkan kualitas asam minyak sawit mentah dengan kualitas tinggi sebagai bahan dasar biodiesel. Algoritma M-Apriori tidak dapat membaca data yang bersifat continous, sehingga harus dilakukan transformasi terlebih dahulu, salah satunya menggunakan bantuan teknik discreetization. Asam minyak sawit mentah jenis Esteridikasi yang Kadar asam lemaknya >60 dan Abu tandan 51-100 g/mol maka Kualitas biodiesel dengan ket Hasil naik metil Ester meningkat sebanyak 100\% (confidence: $1>70 \%$ ). Asam minyak sawit mentah jenis Esteridikasi yang digabung dengan Asam minyak sawit mentah jenis trasesterfikasi belum memiliki keterkaitan yang signifikan dikarenakan tidak bisa mendapatkan metil ester yang senyawa.

\section{REFERENSI}

[1] J. B. I. T. N. A. \&. M. A. Nduwayezu, "Biodiesel production from unrefined palm oil on pilot plant scale," International Journal of Sustainable and Green Energy, pp. 11-21, 2015.

[2] A. prajana, "perbandingan manajemen laba terhadap persistensi laba pada perusahaan perbankan yang go publik di bursa efek indonesia,” Jurnal Sistem Informasi dan Teknologi (JST), pp. 21-28, 2011. 
[3] e. a. Thabtah, "A New classification based on Association algoritm," Journal of information and knowledge managemen, vol. 9, no. 1, pp. 55-64, 2010.

[4] Agus, "K-means penerapan, permasalahan dan metode terkait," Jurnal sistem dan informatika ,pp. 47-60, 2007.

[5] Sheeehan, "An Overview of biodiesel and Petroleum Diesel Lifecycles," Natural Diesel, pp. 20-29, 2012.

[6] S. Migas, "Mengelola migas untuk kepentingan bangs," BUMN Migas, Indonesia, 2013.

[7] B. Widarsono, "Cadangan dan prosuksi gas bumi Nasional: sebuah analisa atas potensi dan tantangannya," Jurnal lembaran publikasi Minyak dan gas bumi, pp. 11-26, 2013.

[8] Jiawei, "Data mining: Concepts and Tecniques," Morgan Kaufmann Publishers is an imprint of Elsevier, San Fransisco, 2006.

[9] Abdel, "Associative classification Approaches: Review and Comparison," Journal of internasional \& Knowledge manageme, vol. 13, no. 13 , pp. 1-30, 2014

[10] Agrawal, "Fast Algoritmhm for Mining Association Rule," dalam VLDB Conference, 1994.

[11] M. e. a. Al-Maolegi, “ An Improving an Association Rules,” Internasional Journal on natural language Computing, pp. 20-29, 2014.

[12] F. C.-Q. A. C.-B. J. A.-U. C. C.-M. G. C.-B. R. \&. M.-R. C. Anguebes-Franseschi, "Optimization of biodiesel production from africa crude plam oil with high concentration of free fatty acids by a two-step transesterification process," Open journal of ecology, p. 13, 2016.

[13] Liu,et al, "improving an Association Rule Based Classifier," dalam Proceedings of the 4th European Conference on Principles of Data Mining and Knowledge Discovery, Lyon, France, September 2000. 